\section{Influence of Inner Circular Sealing Area Impression Method on the Retention of Complete Dentures}

\author{
Cun-Wei Wang ${ }^{1}$, Qi Shao ${ }^{2}$, Hui-Qiang Sun ${ }^{1,3}$, Meng-Yun Mao' ${ }^{1}$ Xin-Wei \\ Zhang $^{1}$, Qi Gong ${ }^{1}$, Guo-Ning Xiao ${ }^{1}$
}

'College of Stomatology, Shandong University, Jinan, Shandong, China ${ }^{2}$ Weihai Municipal Hospital, Weihai, Shandong, China ${ }^{3}$ Shandong Provincial Key Laboratory of Oral Biomedicine, Shandong, China

Correspondence: Vice Prof. Huiqiang Sun, Wenhuaxi Road 44-1\#, 250012 Jinan, Shandong Province, China. Tel: +86-139-6918-1267; +86-0531-88382058(0). e-mail: whitedove69@163.com

\begin{abstract}
The aims of the present study were to describe an impression method of "inner circular sealing area" and to evaluate the effect of the method on retention, aesthetics and comfort of complete dentures, which lack labial base for patients with maxillary protrusions. Three patients were subjected to the experiment, and two sets of complete maxillary dentures were made for each patient; the first set was made without labial base via an inner circular sealing area method (experimental group) and the second had an intact base that was made with conventional methods (control group). Retention force tests were implemented with a tensile strength assessment device to assess the retention and a visual analogue scale (VAS) was used to evaluate the comfort between the two groups. Results showed larger retention force, better aesthetics and more comfort in the experimental group. The improved two-step impression method formed an inner circular sealing area that prevented damage to the peripheral border seal effect of the denture caused by incomplete bases and obtained better denture retention.
\end{abstract}

Key Words: complete denture, retention, retention force test, protrusive maxillary alveolar ridge, aesthetics.

\section{Introduction}

Darvell and Clark (1) advocated that surface tension forces at the periphery contribute to retention, but the most important concerns for retention are good base adaptation and a good border seal. These efforts were all based on accurate impressions. Various impression methods can be used to make complete dentures. A recent survey (2) revealed selective pressure was the predominantly used impression philosophy in US postdoctoral prosthodontic programs. The selective-pressure technique applies stress to areas that can best resist the functional forces of the denture bases, while minimal pressure is applied to the other areas (3). Most of the selective-pressure impression methods involve improvements compared to the functional impression technique due to the creation of custom trays, border molding, or utilization of new materials (4). Malachias et al. (5) created a removable acrylic resin tray handle that can be attached to custom impression trays to produce an accurate peripheral sealing zone using the patient-conducted muscular motion technique. However, the former studies of selective-pressure techniques have primarily concentrated on the posterior palatal seal and neglected the other movable tissue areas.

This paper reports three cases of edentulous patients with maxillary protrusions wearing complete dentures, in which an improved selective-pressure impression method - the inner circular sealing area impression method - was adopted to change the position of border seal. In the three cases, the intention was to eliminate the negative effect of the labial base on the aesthetics and comfort, while a tensile strength test was applied simultaneously to prove no reductions in retention due to base defects.

\section{Case Report}

Based on the oral and economic conditions, and individual requirements, were chosen three edentulous subjects with maxillary protrusions who were referred for treatment in the Department of Prosthetic Dentistry at the Stomatological Hospital of Shandong University, China. Two men and one woman with a mean age of 54 years were included in the study. The patients were healthy adults with no systemic or salivary gland diseases. Two sets of complete dentures were made for each patient; the first set was made without a labial base for aesthetic considerations via an inner circular sealing method (experimental group), and the second had an intact base constructed in a conventional manner (control group). In order to evaluate the new impression method, a tensile strength test was applied to evaluate the retention and comfort was assessed using a visual analogue scale (VAS). Next, details of the results observed in one example patient were provided.

The patient was male and 53 years old. His maxillary alveolar ridge was in good condition and the anterior region was rich (Fig. 1). He had a maxillary protrusion profile when wearing his old typical maxillary complete denture.

For the control group, the wash portion of silicone rubber (Silagum Light Abformmaterial Impression material; DMG, Hamburg, Germany) was used to create a closed- 
mouth impression with the old complete denture. A twostep impression method served as the experimental group. First, silicone rubber putty (Rapid Soft silicone rubber

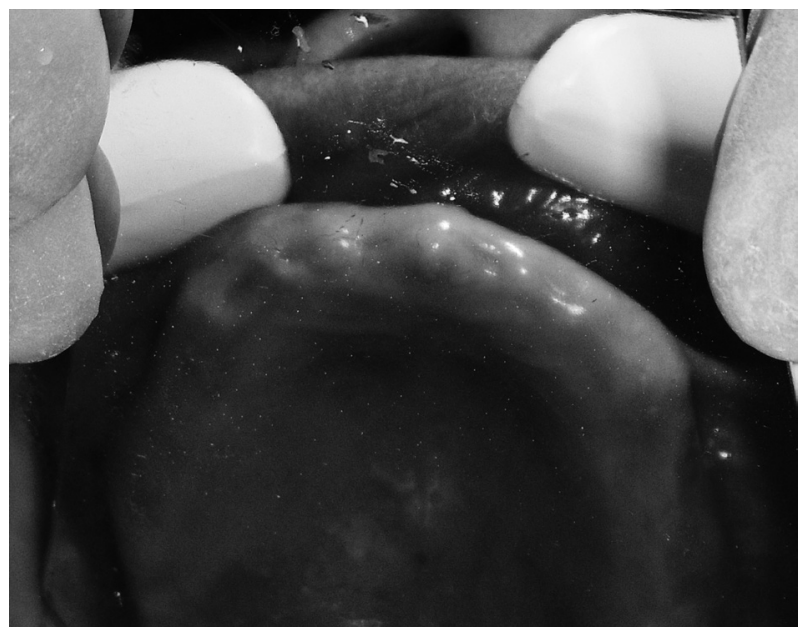

Figure 1. Rich maxillary ridge, particularly in the labial portion.
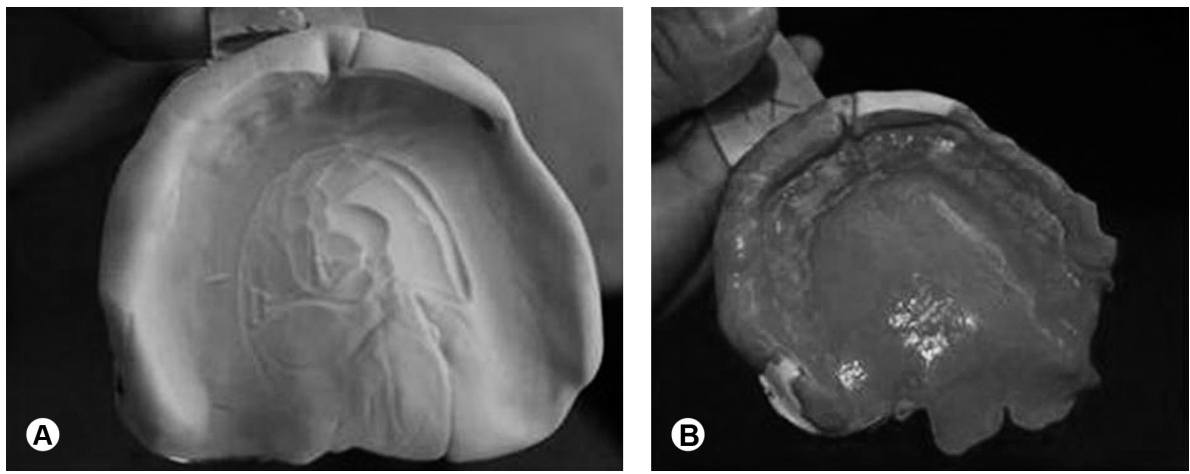

Figure 2. A: Material was removed to a depth of approximately $1 \mathrm{~mm}$ within the secondary stress-bearing area and the palatal vault. B: Final impression.

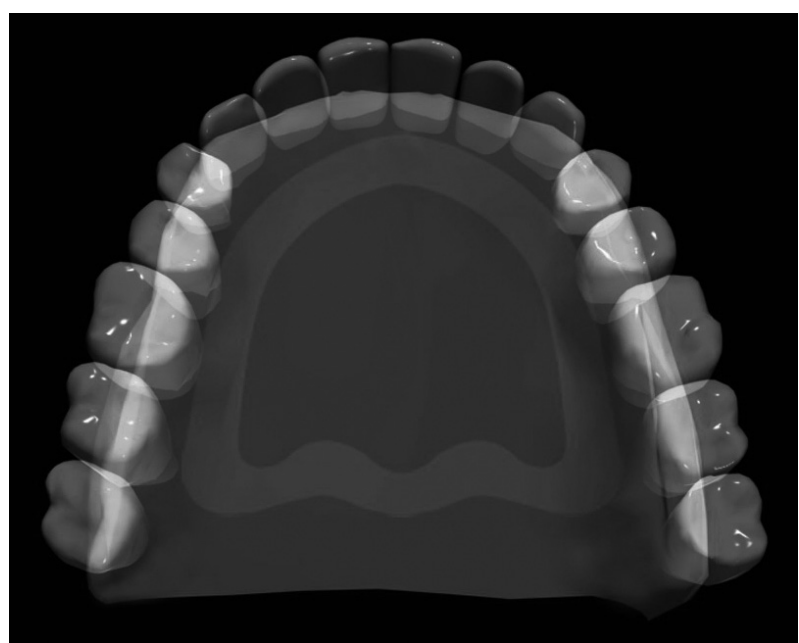

Figure 3. Diagrammatic representation of a maxillary complete denture. The circular area inside the dentition indicates the location of the inner circular sealing area. impression material; Coltene/Whaledent AG, Altstatten/ Switzerland) was used to make an initial impression, and the impression material was then removed to a depth of approximately $1 \mathrm{~mm}$ in the area that corresponded to the secondary stress-bearing area and the palatal vault (Fig. 2). Second, the wash portion of the silicone rubber was poured into the obtained impression to produce a final impression. The selective-pressure technique applied here was defined as "the inner circular sealing area impression method". During the operation, appropriate clinical pressure was applied at the alveolar ridge. The occlusion relation was recorded with red wax sheets (Dental Material Factory; Shanghai Medical Instruments Co., Shanghai, China), and this relationship was applied to the articulator. Figure 3 presents a diagrammatic representation of a maxillary complete denture with the location of the inner circular sealing area.

After arranging the teeth of the control group, a heavy silicone rubber putty was used to make an index impression that was used to obtain a standard of teeth position relationship for the two sets of dentures. The other procedures of the denture construction including the maxillomandibular relations, the laboratory procedures for investing, packing, polishing and the adjustments procedures were the same for both groups and proceeded according to the conventional methods, and will not be described in details here.

When the dentures were finished, a metal ring was fixed at the center of the triangle formed by the maxillary central incisors and left and right first molars with the self-curing acrylic resin for each set of dentures (Fig. 4A). A mandibular tooth arch traction and retention device was made with self-curing resin to create an individual tray on the mandibular working cast. The left and right sides of the dental arch were connected with a cross bar corresponding to the metal ring (Fig.4B). The metal ring on the maxilla was connected to the gauge (AIGU Digital Force Gauge; GTGY Group Co., Hong Kong, China) with a metal wire that was rounded across bar to create denture dislocation traction that transferred the traction in the vertical direction to the horizontal direction out of the mouth (Fig. 4C). Denture retention is regarded as a time-dependent dynamic process influenced by many factors (6). Thus, the tensile test must be performed by the 
same operator at the same speed to reduce the influence of time. The tensile tests were the same for both groups and were done by the same operator blinded to the patient's treatment group, supervised by prosthodontist. A uniform tensile load was applied in the vertical direction and the maximal tensile force used to dislocate the denture was recorded. The measurements were repeated three times. The metal ring was removed after the retention test.

The completed dentures are shown in Figure 5, and the maxillary protrusion profiles of the patient wearing the dentures are shown in Figure 6. The maxillary protrusion was greatly improved for the patient wearing the dentures
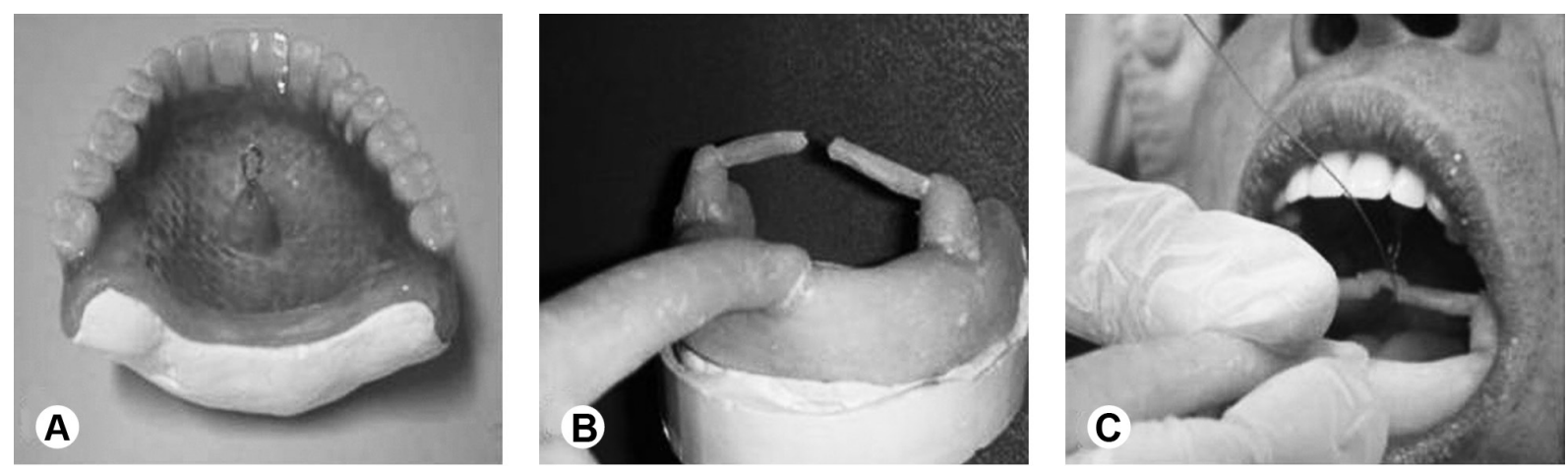

Figure 4. A: The metal ring placed on the maxillary denture base. B: The mandibular tooth arch traction and retention device. Individual mandibular tray made of self-curing resin with a bow-shaped rod connected both sides of the arch at the first molar position. The middle part of the cross bar should be pasted around to form an arch shape with self-curing resin preventing the metal wire from moving sideway when testing the retention force. C: A metal wire was fixed on the metal ring placed on the maxillary denture base (A), passing downward around the cross bar (B) and then extended horizontally outward to connect the device of the tension test gauge.
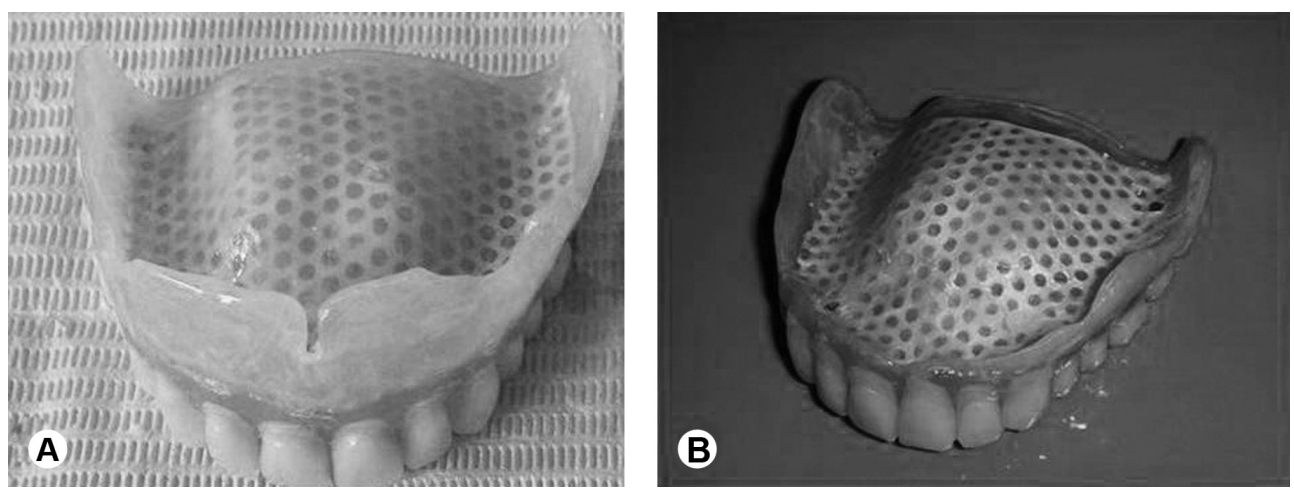

Figure 5. A: Control group: dentures with an intact base made according to the conventional method. B: Experimental group: dentures without a labial base made with the inner circular sealing area impression method.
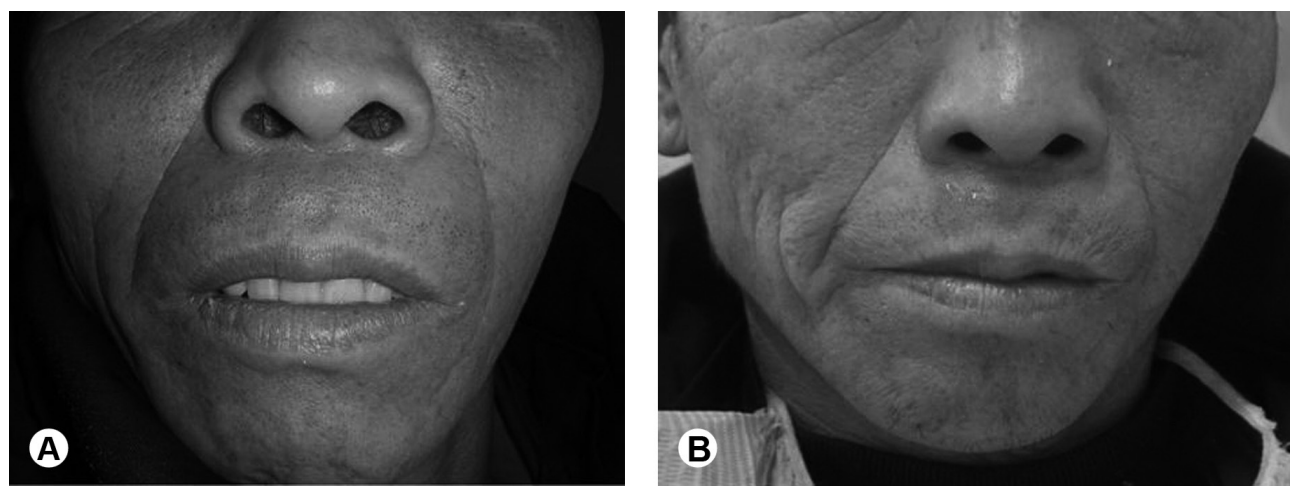

Figure 6. A: The appearance of the patient while wearing the control dentures. B: The appearance of the patient while wearing the experimental dentures. The aesthetics of the experimental dentures were superior to those of the control dentures. 
without a labial base. The comfort satisfaction scores of the experimental group were higher than that of the control group.' The patient was satisfied with the experimental dentures.

The results of tests conducted with the traction device are shown in Figure 7. Data were analyzed statistically using the paired t-test at 5\% significance level. In the clinical situation presented herein, the retention force of the experimental dentures was significantly improved $(p<0.05)$ compared with the control dentures. There were statistically significant differences $(p<0.05)$ among patients within control and experimental groups respectively, and the discrepancy on patients' physiological conditions such as the alveolar ridges or saliva viscosities and amounts may account for the differences.

\section{Discussion}

The objectives of any prosthodontic service are to restore the patient to normal function, contour, aesthetics, speech and health (7). The achievement of complete denture retention requires the intimate adaptation of the denture base to its underlying supporting structure $(1,8)$, a good border seal that is achieved by extending the denture flanges to fill the sulci $(1,9)$, and neuromuscular balance (10). Gonçalves et al. (11) suggested the use of intramucosal zirconia inserts to provide adequate retention and stability of the complete denture and comfort to the patients. For aesthetic reasons, the labial base of the denture can be removed, but this can reduce the quality of the border seal and compromise the retention of complete dentures (12). Thus, the formation of a new sealing structure on the tissue surface was essential to account for the removal of the labial base.

In the control group, was used the old complete denture

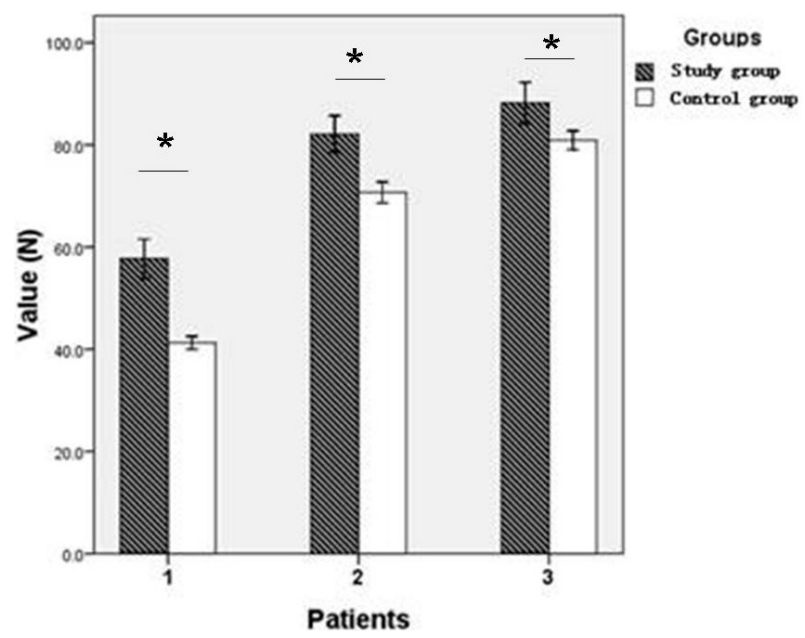

Figure 7. Tensile test results for the experimental and control dentures. The asterisk indicates a statistically significant difference at $p<0.05$. as an individual tray to make a closed mouth impression. The closed mouth impression techniques permit forming surfaces of the base of complete dentures under mastication pressure, and the mucosa of alveolar ridge obtained with the mouth closed could maximally approximate to those while the denture were used (13). The complete denture created by this method should be more suitable, but the results of the tensile test in the control group were worse than those of the experimental group. The primary stressbearing area was covered with keratinized mucosa, which lacks elasticity and remains stable when pressure is applied, while the mucosa on the secondary stress-bearing area was thicker and soft and thus had a poor bearing capacity (14). The stresses on mucosa are different in various regions due to dissimilar thicknesses (15). For final impressions in the experimental group, the use of selective pressure techniques that place pressure on stress-bearing areas and place minimum pressure on non-stress-bearing areas is important (16). Under pressure, the wash portion of silicone rubber on top of the alveolar ridge will flow away, while the mucosa of the secondary stress-bearing area will not be stressed or will bear little pressure compared to that of the control group because of the previous scrape and the good flow properties of the silicone rubber. The mucosa does not deform or move and can thus fit closely to the complete denture base, which eliminates the denture dislocation caused by the return of the mucosa to its original position. The outer third of the palatal mucosa extends with the top of the alveolar ridge to the rear portion where it combines with the transverse anterior vibrating line area to form an annular region and improves the seal of the denture base; this region is called the "inner circular sealing area"(Fig. 2).

The existence of the inner circular sealing area results in the close adaptation of the surface of the denture base to the mucosa, which could compensate for the decrease in retention force caused by the disrupted labial border seal. Therefore, when the complete denture is exposed to mastication pressure, the alveolar ridge will support the denture on one hand, and on the other hand, deformation of the mucosa within the inner circular sealing area is avoided. Moreover, this type of complete denture meets the patients' aesthetic requirements.

During the two-step impression process, the quantity and range of impression material that is scraped away should be given particular attention. Specifically, at least $1 \mathrm{~mm}$ of depth is needed in principle. Otherwise, it will be difficult to completely relieve the pressure on the secondary stress-bearing area. Additionally, a research has shown that excessive pressure can block the palatine gland duct, which might ultimately cause gland destruction (17). As an important mucosa gland, the palatine gland is important for maxillary denture retention (18). The range of the areas that 
is scraped from the impression includes the entire secondary stress-bearing area of the palate and the palatal vault, and the primary stress-bearing area must not be scraped. If the material of putty individual tray corresponding to primary stress-bearing area, including alveolar ridge crest, were scraped, the due pressure cannot be applied to these areas when making selective pressure impression and the shape of the alveolar ridge at functional state under mastication pressure would not be correctly obtained.

This improved two-step impression method that forms a new palatal inner sealing area can be successfully utilized in complete denture treatments because it provides better maxillary denture retention. Additionally, this method may improve the aesthetic appearance and comfort of patients with maxillary protrusions.

\section{Resumo}

0 objetivo deste caso foi descrever um método de impressão por "área de selamento circular interno" e avaliar o efeito deste método na retenção, estética e conforto de próteses totais sem base labial para pacientes com protrusão maxilar. Três pacientes foram objeto desta experiência e foram feitas duas próteses maxilares completas para cada um deles; a primeira foi elaborada sem base labial pelo método de área de selamento circular interno (grupo experimental) e a outra teve uma base feita pelo método convencional (grupo controle). Foram realizados testes de retenção com ¿ estudo de tensão para avaliar a retenção e para avaliação do conforto dos dois grupos, foi empregada a escala analógica visual (EAV). Os resultados demonstraram que o grupo experimental apresentou força de retenção maior, estética melhor e mais conforto. 0 método modificado de impressão em duas etapas formou uma área de selamento circular interno que evitou

$\cup$ danos ao selamento periférico causados por bases incompletas e obteve melhor retenção da prótese.

\section{Acknowledgements}

The authors have no conflicts of interest related to this study to declare. Special thanks to Ms. Heng Liu of the Department of Prosthodontics, Weifang Medical University, Shandong, China, for performing the clinical photography during her study period at the College of Stomatology, Shandong University.

\section{References}

1. Darvell BW, Clark RK. The physical mechanisms of complete denture retention. Br Dent J 2000;189:248-252.
2. Mehra $M$, Vahidi F, Berg RW. A complete denture impression technique survey of postdoctoral prosthodontic programs in the United States. J Prosthodont 2014;23:320-327.

3. Duncan JP, Raghavendra S, Taylor TD. A selective-pressure impression technique for the edentulous maxilla. J Prosthet Dent 2004;92:299301.

4. Hayakawa I, Watanabe I. Impressions for complete dentures using new silicone impression materials. Quintessence Int 2003;34:177-180.

5. Malachias A, Paranhos HF, da Silva CH, Muglia VA, Moreto C. Modified functional impression technique for complete dentures. Braz Dent J 2005;16:135-139.

6. Murray MD, Darvell BW. The evolution of the complete denture base. Theories of complete denture retention--a review. Part 3. Aust Dent $J$ 1993;38:389-393.

7. Hina Z, Raja, Saleem MN. Neutral zone dentures versus conventional dentures in diverse edentulous periods. Biomedica 2009;25:136-145.

8. Nirale RM, Thombre R, Kubasad G. Comparative evaluation of sodium hypochlorite and microwave disinfection on dimensional stability of denture bases. J Adv Prosthodont 2012:4:24-29.

9. Mayada $\mathrm{Q}$, Khafoor A. A comparison of the retention of complete denture bases having different types of posterior palatal seal with different palatal forms. J Bagh College Dentistry 2012;24:11-17.

10. Badel T, Robert Ćelić, Sonja Kraljević, Josip Pandurić, Nikša Dulčić. Complete Denture Remounting. Acta Stomatol Croat 2001;35:381-387.

11. Gonçalves F, Dias EP, Cestary TM, Taga R, Zanetti RV, Zanetti A, et al.. Clinical and histopathological analysis of intramucosal zirconia inserts used for improving maxillary denture retention. Braz Dent $J$ 2009:20:149-155.

12. Clark RK, Radford DR. Immediate replacement complete dentures: pitfalls of ignoring traditional teaching and established practice. Eur J Prosthodont Restor Dent 2011;19:131-134.

13. Savvidi GL. A modified method for the volumetric modelling of the base for a complete removable denture. Stomatologiia 1997;76:37-39 (in Russian).

14. Hu YP, Yu SY. Characteristics of the edentulous mucosa. International J Stomatol 1993;20:159-162.

15. Cheng YY, Cheung WL, Chow TW. Strain analysis of maxillary complete denture with three-dimensional finite element method. J Prosthet Dent 2010;103:309-318.

16. Rao $\mathrm{S}$, Chowdhary R, Mahoorkar S. A systematic review of impression technique for conventional complete denture. J Indian Prosthodont Soc 2010;10:105-111.

17. Ostlund SG. Palatine glands and mucin: Factors influencing the retention of complete dentures. Odontol Tidsk. 1954;62:1-128.

18. Shiba A, Sano K, Nakao M, Yoshida J, Cho H, Hayashi T. Electrophoretic analysis of the protein in palatine saliva. J Prosthet Dent 1980;43:385391. 